\title{
Issues, Concerns and Directions for Improving the Quality of Higher Education in India
}

\author{
Naveen S. Singh \\ Associate Professor, Department of Zoology, Lucknow Christian College, Lucknow-226018
}

\begin{abstract}
The higher education system in India has undergone a huge change since independence. It has long been defined by its rote-learning method and textbook-centric teaching. The archaic learning pattern has been blamed for taking away creative thinking from the young minds which makes them hesitant from embracing creative careers. There have been some changes in the education system in the recent years, like the CBSE's introduction of art-integrated courses. Higher education system in India is one of the world's largest systems of education in terms of students, which has a great potential to compete with global universities. It is one of the key drivers of growth performance, prosperity, and competitiveness in national and global economies. Education empowers minds that will be able to conceive good thoughts and ideas as it is the key to success in life, and teachers make a long lasting impact. It has been widely acknowledged that no country can alleviate poverty, achieve sustainable economic development and produce skilled human resources without substantial investment in human capital. This study aims to highlight the challenges and the opportunities in higher education system in India and to analyses the various factors which are important for a country to provide word-class education with international norms. It takes stock of the initiatives taken by the government to improve the standards of higher education.
\end{abstract}

Keywords: Education, Opportunities, Challenges, Governance, Development, Colleges, Universities

DOI: $10.7176 / \mathrm{JEP} / 11-22-03$

Publication date:August $31^{\text {st }} 2020$

\section{Introduction}

Today, the scenario of academia in India is changing and expanding with the globalized system of education and universities and university level institutions facing a veritable explosion of knowledge and technology in all fields. The higher education sector in India consists of 3.74 crore students across 993 universities, 39,931 colleges, and 10,725 stand-alone institutions, according to the AISHE-2019 (Sharma 2020). Education is the main tool for investment in human capital development. Moreover, it makes individuals more responsible for contributing in the development of any economic sector in a country (UGC, 2003). It is important for the personal, social and economic development of the nation as well

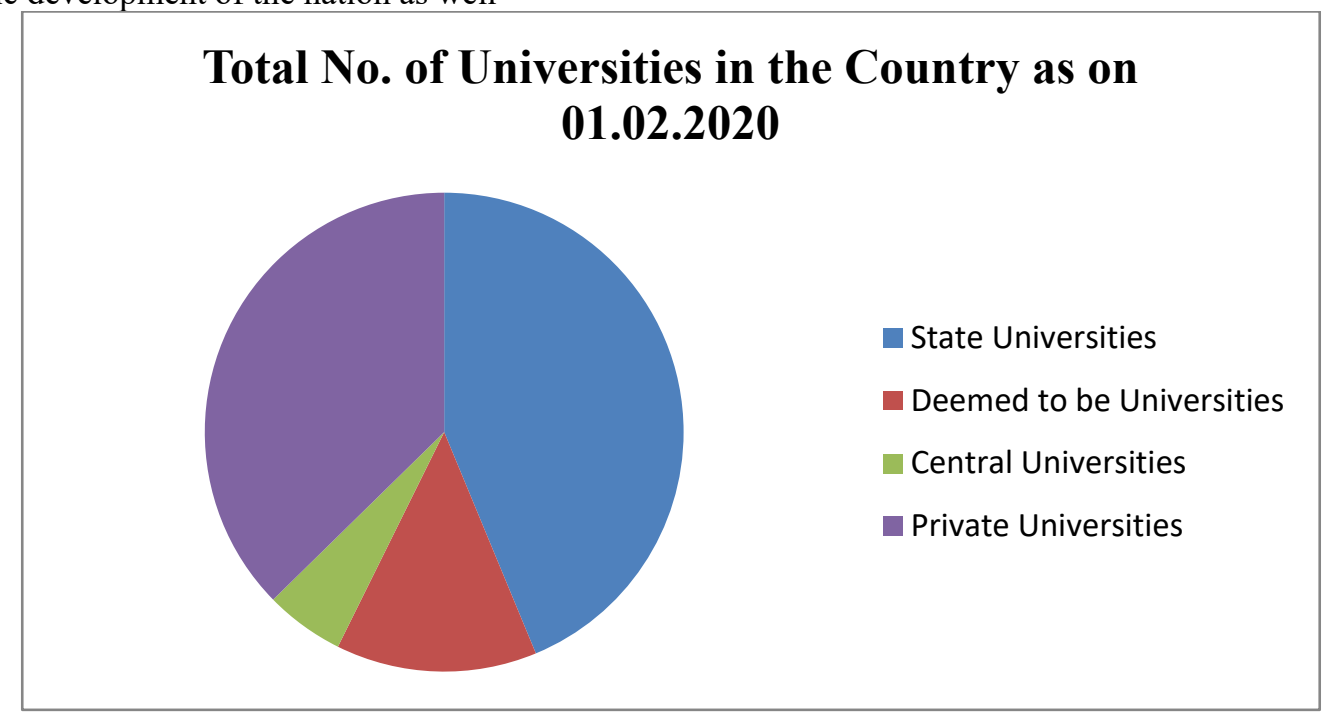

Source: https://www.ugc.ac.in/oldpdf/Consolidated\%20list\%20of\%20All\%20Universities.pdf

as to live with happiness and prosperity. Across the world, higher education is expected to change to match changes in their host environment. In the developed countries, the value of higher education is often questioned for resources expended, while in developing countries, education institutions are particularly valued for the contribution they can make towards national development. Education also enables students to analyze and make choices of their lives. Some higher education institutions offer adult education and leisure courses, upper secondary courses to prepare students for tertiary-level study, and short specific occupational preparation at sub-degree level (OECD, 2008). 
We experience several events in our daily lives that are examples of kindness, brotherhood, fraternity and tolerance. Despite all that, moral and ethical degradation is posing significant challenge to almost all the social corners of the country. Modern world is the witness of unprecedented value erosion despite educational and technological progress. The role of higher education institutions in today's world is immense, complex and vital. A wide range of challenges and opportunities are emerging, that have political, economic and social implications. Perhaps, the most significant are the challenges associated with shifting perspectives of knowledge itself, which are strongly influencing the role and the responsibility of universities in our society.

"No country can really develop until its citizens are educated." - Nelson Mandela

Undoubtedly, getting higher education increases the scope of people's skills and knowledge, which in turn paves way for innovation, productivity, creativity, thereby fuelling entrepreneurship and technological developments. Educated citizens can be the key determinant of a nation's development which builds the economy and contributes in poverty reduction. It is perceived that quality education and economic performance are directly related in terms of improvement. Therefore, this paper attempts to highlight the recent improvements and current challenges in the higher education sector of India and discusses its role in the economic development of the country.

During the $150^{\text {th }}$ year celebration of the Madras University, the President of India Dr. A.P.J. Abdul Kalam stated that higher education would have to be continuously innovative, and make use of modern technology. He emphasized that research and inquiry, creativity and innovation, use of high technology, entrepreneurial and modern leadership were synonymous with the notion of a good educational model.

\section{Substantial Reforms}

More fundamental changes will take longer to achieve but could eventually yield even greater gains in the quality of undergraduate education. They include the following:

Improving graduate education: Colleges and universities need to reconfigure graduate programs. Universities have already begun to prepare graduate students to teach by giving them opportunities to assist professors in large lecture courses and by creating centers where they can get help to become better instructors.

However, today many Ph.D. holders find employment in colleges that are chiefly devoted to teaching or work as adjunct instructors and are not expected to be research oriented. To improve the quality of Indian higher education institution can be accelerated through the approaches like strong institutional governance and high quality leadership (Sengupta \& Haldar, 2014). Rashtriya Uchchatar Shiksha Abhiyan (RUSA) in its report (2013) has stressed that academic leadership is an "area of deficiency".

A more substantial preparation is required and will become ever more necessary as the body of relevant knowledge continues to grow. With all the talk in graduate school circles about preparing doctoral students for jobs outside academe, one has to wonder why departments spend time readying Ph.D. candidates for entirely different careers before they have developed adequate programs for the academic posts that graduate schools are supposed to serve, and that most of their students continue to occupy.

Creating a teaching faculty: The seeds of such a change already exist through the proliferation of instructors who are not on the tenure track but are hired on a year-to- year basis or a somewhat longer term to teach basic undergraduate courses. Those adjunct instructors now constitute as much as 70 percent of all college instructors. The multiplication of such instructors has largely been an ad hoc response to the need to cut costs in order to cope with severe financial pressures resulting from reductions in State support and larger student enrollments. But researchers are discovering that relying on casually hired, part-time teachers can have adverse effects on graduation rates and the quality of instruction. Sooner or later, the present practices seem bound to give way to more satisfactory arrangements. One plausible outcome would be to create a carefully-selected, full-time teaching faculty, the members of which would lack tenure but receive appointments for a significant term of years with enforceable guarantees of academic freedom and adequate notice if their contracts are not renewed. Such instructors would receive opportunities for professional development to become more knowledgeable and proficient as teachers, and they would teach more hours per week than the tenured faculty. In return, they would receive adequate salaries, benefits and facilities and would share in deliberations over educational policies though not in matters involving research and the appointment and promotion of tenure-track professors.

Progress may have to come gradually as finances permit. But instead of today's legions of casually hired, underpaid and insecure assistant instructors, a substantial segment of the college faculty would possess the time, training and job security to participate in a continuing effort to develop more effective methods of instruction to engage their students and help them derive more lasting value from their classes.

Re-thinking the undergraduate curriculum: The familiar division into fields of concentration, electives and general education leaves too little room for students to pursue all of the objectives that professors themselves deem important for a well-rounded college education. This tripartite structure, with its emphasis on the major and its embrace of distribution requirements and extensive electives, was introduced by research universities and designed more to satisfy the interests of a tenured, research-oriented faculty than to achieve the various aims of a good undergraduate education. The existing structure is unlikely to change so long as decisions about the curriculum 
remain under the exclusive control of the tenure-track professors who benefit from the status quo.

The obvious remedy is to include the non-tenure-track instructors who currently make up a majority of the teaching faculty in curricular reviews so that all those who play a substantial part in trying to achieve the goals of undergraduate education can participate in the process. It is anomalous to allow the tenure-track faculty to enjoy exclusive power over the curriculum when they provide such a limited share of the teaching. Such a reform might be difficult under current conditions in many colleges where most undergraduate instructors serve part-time, are often chosen haphazardly, and frequently lack either the time or the interest to participate fully in a review of its undergraduate program. If adjunct instructors achieve the status previously described, their prominent role in teaching undergraduates should entitle them to a seat at the table to discuss the educational program, including its current structure. Such a move could at least increase the likelihood of a serious discussion of the existing curricular structure to determine whether it truly serves the multiple aims of undergraduate education.

Colleges should also consider allowing some meaningful participation by members of the administrative staff who are prominently involved in college life, such as deans of student affairs and directors of admission. The current division between formal instruction and the extra-curriculum is arbitrary, since many goals of undergraduate education, such as moral development and preparation for citizenship, are influenced significantly by the policies for admitting students, the administration of rules for student behavior, the advising of undergraduates, the nature of residential life and the extracurricular activities in which many students participate. Representatives from all groups responsible for the policies and practices that affect these goals should have something to contribute to the reviews of undergraduate education.

\section{The Need for Research}

There is an urgent need for more and better research both to improve the quality of undergraduate education and to increase the number of students who complete their studies. Among the many questions deserving further exploration, four lines of inquiry seem especially important:

- How can remedial education be improved? At present, low rates of completion in remedial courses are a major impediment to raising levels of educational attainment. The use of computer-aided instruction in remedial calculation provides promising example of the type of improvement that could yield substantial benefits.

- Far too little is known about the kinds of courses or other undergraduate experiences that contribute to such noneconomic benefits in later life as better health, greater civic participation and lower incidence of substance abuse and other forms of self-destructive behavior. Better understanding of those connections could help educators increase the lasting value of a college education while providing a stronger empirical basis for the sweeping claims frequently made about the lifelong benefits of a liberal education. Such understanding would also reduce the risk of inadvertently eliminating valuable aspects of a college education in the rush to find quicker, cheaper ways of preparing students to obtain good jobs of immediate value to economic growth.

- Existing research suggests that better advising and other forms of student support may substantially enhance the effect of increased financial aid in boosting the numbers of students who complete their studies.

- More work is needed to develop better ways for colleges to measure student learning, not only for critical thinking and writing but also for other purposes of undergraduate education.

The importance of this last point can hardly be overestimated. Without reliable measures of learning, competition for students can do little to improve the quality of instruction, since applicants have little way of knowing which college offers them the best teaching. Provosts, deans, departments and other administrative heads have difficulty in identifying weaknesses in their academic programs and require corrective action. Academic leaders will be handicapped in trying to persuade their professors to change the way they teach if they cannot offer convincing evidence that alternative methods will bring improved results.

Teaching was mostly considered as a research-dependent activity, teaching was self-evident. The traditional reward system, primarily based on scientific performance (e.g. publications) lacked concern about quality teaching. This trend therefore overlooked the purpose of teaching, while research drew the attention of leaders, researchers, politicians and funding councils. This trends has been regularly explored and even denounced by scholars, like Gibbs who has asked that the same quality enhancement processes already used for research be applied to teaching, such as peer review, rewards for excellence, co-operative work, and incentives to read and discuss the literature. He stated that teachers should receive training, funding and access to better facilities (Gibbs, 1995). All these reforms could do a lot to improve the quality of undergraduate education as well as increase levels of attainment. With more research and experimentation, other useful ideas will undoubtedly continue to appear.

\section{The challenges}

Despite the cited quantitative immense growth during the past over one decade, the Indian subcontinent suffers 
from severe challenges on the road to organize its higher education system for the best possible economic development. In 2012, former UN diplomat Shashi Tharoor said, "India is entering the global employment marketplace with a self-imposed handicap of which we are just beginning to become conscious - an acute shortage of quality institutions of higher education. For far too long, we have been complacent about the fact that we had produced, since the 1960s, the world's second largest pool of trained scientists and engineers." (Implementing Quality in Higher Education, 2012).

\section{Suggestions for the Improvement of the Quality of Higher Education}

Following are the measures necessary to improve the quality of education and research in higher education institutions in India:

- Offer need based and value based academic programs of studies which are interdisciplinary in their approach.

- Maintain highest standards in teaching and learning, complacent care and the extracurricular programs so that each student thrives to do their best.

- Organize academic activities to create conditions for focused attention to the development of specific disciplines and advancement of knowledge through cross fertilization of ideas and by bringing together various interdisciplinary approaches.

- Enhance the quality of teaching and learning according to global standards and all other dimensions, viz. curriculum areas, by means of innovative pedagogical practices and cutting-edge technology through accreditation with concerned bodies in all fields.

- Meet the global benchmarks in terms of educational facilities, physical infrastructure and research environment.

- Import quality education, sound learning and extensive corporate exposure to the students which would ensure their holistic development.

- Exercise effective control on expenditure to remain financially-stable, thereby continuing to offer good value for money to all stakeholders.

- Recruit and retain the best staff, and enhance the capacity to promote our staff so that they feel fulfilled and supported, as well as equipped.

- Take appropriate measures for promoting innovations in the teaching-learning process, inter-disciplinary studies and research.

- Develop boarding for foreign students, including the ongoing upgrading of facilities for students and staff.

- Maintain and develop our infrastructural resources to provide the highest quality of facilities for the education we wish to offer.

- Ensure a pleasant working environment for all members of the community.

The institutes should start skill based add on vocational courses for the vertical mobility of the students. Choice based credit programs should be properly implemented.

The institute should promote International Strategic Partnership and collaborations with leading universities and business schools which shall include:

- $\quad$ Student exchange program

- $\quad$ Faulty exchange program

- Joint monographs

- Joint publications in the form of international journal and edited books.

- Joint research on contemporary issues

The institutes should have a social conscience to fight for downtrodden, and underprivileged students and society at large. They should undertake the extension work with NGO's, state government, central government and other agencies in the areas of gender equality economic self-reliance of women, girl education, population issue, issue of women rights, social exploitation, sexual harassment, female foeticide mental health and general awareness.

The institutes should provide in-house training in the areas of communication, public speaking skills, creativity and innovation, team building, leadership effectiveness, stress management, time management, art of negotiation etc.

Higher education institutions are critically important here. Universities should be proactive in arranging opportunities for current students to develop industrial expertise through work experience and internships. In addition, technological and workplace skills training should be taught along with an academic curriculum. Further, it can be beneficial to offer mentoring opportunities to help prepare expectant graduates for a competitive job market.

Knowledge really is power, but it's not just about formal academic qualifications. Broad employability skills help graduates give employers precisely what they need: technologically-minded workers who are flexible, organized, and resourceful. In addition, universities are ideally-placed to offer employability training to people 
looking to change careers or apply for new roles, who need an update to their existing skills. Advanced courses for experienced professionals also represent an exciting intersection for higher education and industry.

Online courses at Swayam Portal should be promoted so that students can experience learning anytime and anywhere. Today, India is one of the fastest developing countries of the world with the annual growth rate going above $9 \%$. In order to sustain the rate of growth, there is need to focus on the quality of higher learning. Presently, only few institutions in India are able to compete with the quality standards of World Ranking Organizations like THE, QS and ARWU. There is no Indian higher educational institute that is positioning itself in the top 100 universities of the world. In order to strive and thrive, there is an urgent need to relook the financial resources, quality standards, access and equity, and relevance of research. Therefore, in order to attain and sustain national, regional or international quality, certain factors are relevant which demand careful attention like skill development, sound teaching and learning for holistic development, physical infrastructure and research environment, innovative pedagogical practices, vocational education, cross-disciplinary and multidisciplinary engagement etc.

Finally, here are a few lines of a popular poem that was once also cited by A.P.J. Abdul Kalam

"When you wish upon a star,

Makes no difference who you are,

Anything your heart desires

Will come to you"

\section{Conclusion}

In a nutshell, the Indian education system should change in accordance with the changing times and it is high time that the teachers, students, government and intellectuals realize their responsibilities to ensure a bright future in the light of applied technological education which is relevant in the long run.

The higher education sector has a wide-ranging, proven influence on the economy. Its confluence with business provides commercial value to innovation, while academic instruction and skills training help individuals and organizations to have the tools to succeed in a knowledge-based economy. Quality has both absolute and relative meanings. The concept of absoluteness in quality props up the moral of the higher education system at the delivering as well as the receiving end i.e. institutional and students respectively.

The quality of a higher education system may be seen from the point of view of norms and standards, which may evolve depending on the need of the hour. The alternative dynamics for teacher preparation and the sustaining quality in teacher input, like: curriculum design and development; Curricular practices vis-à-vis evaluation of learner' performance and progress vis-à-vis curriculum evaluation; and, quality management practices become crucial.

The Indian higher education system, today, is facing strong pressure to show improvements which requires institutional governance, autonomy, and high-quality education, but the matter of the fact is that most of the higher education institutions are unable to meet the global standard. As a result, the need of an extreme new breed of leadership in higher education becomes obvious.

\section{References}

1. Sharma, K. (2020), Study shows how India's higher education enrollment can jump to $65 \%$ from $27 \%$. The Print, 15 June

2. Gibbs, G. (1995), The Relationship between Quality in Research and Quality in Teaching, Quality in Higher Education, Vol. 1, No. 2.

3. OECD (2008), Tertiary Education for the Knowledge Society, Vol. 1, OECD, Paris.

4. UGC (2003) Higher Education in India: Issues, Concerns and New Directions University Grants Commission, New Delhi.

5. RashtriyaUchchatarShikshaAbhiyan. (2013). National Higher Education Mission. New Delhi: GOI, MHRD in association with the Tata Institute of Social Sciences.

6. Sengupta, S., and Haldar, P. K. (2014). Role of Leadership in Governance of Higher Education. In Governance of Multicultural Societies: Issues and Trends (pp. 175-183). Excel India Publishers. 